\title{
PECS I block in a patient without pectoralis major muscle
}

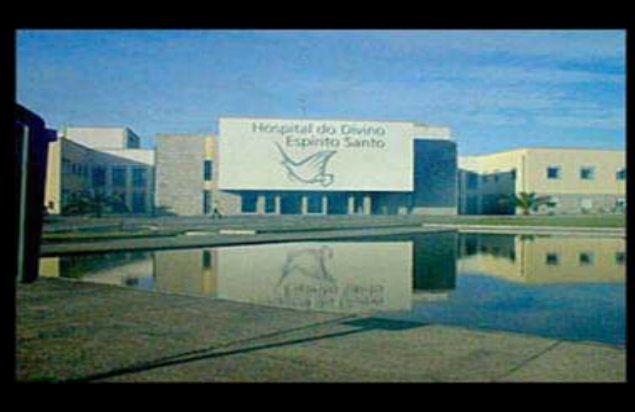

- is it possible?

\section{Cabral $\mathbf{T}^{1}$, Silva $\mathbf{R}^{1}$, Trindade $\mathrm{H}^{2}$, Ferreira $\mathrm{J} \mathrm{L}^{2}$}

${ }^{1}$ Hospital Divino Espírito Santo, Dept. of Anaesthesiology, Ponta Delgada, Portugal

${ }^{2}$ Hospital D. Estefânia, Centro Hospitalar Lisboa Central, Dept. of Anaesthesiology, Lisbon, Portugal

\section{BACKGROUND}

PECS I block was first described in 2011 by Blanco. The purpose of this block is to place local anesthetic into the interfascial plane between pectoralis major and minor muscles ${ }^{(1)}$, providing anesthesia/postoperative analgesia for some thoracic procedures.

\section{CASE REPORT}

We present a case report where we performed PECS I block in a female patient, 7 years old, 22 $\mathrm{Kg}$, ASA II, with Poland syndrome, a rare congenital anomaly ${ }^{(2)}$, who had an aplasia of the pectoralis major muscle and a slight hypoplasia of the hand, both on the left side. She had an anterior axillary fold that limited the extension of the left arm and was proposed to surgical correction by plastic surgery in an outpatient regimen.

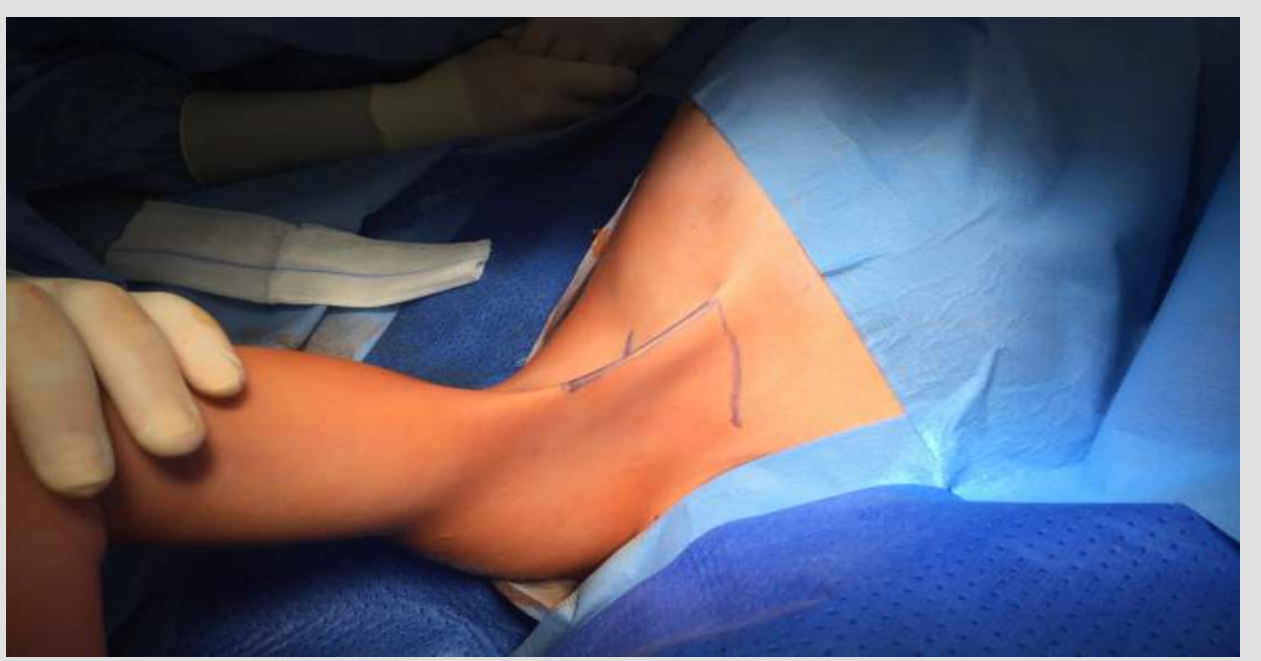

We induced a general anesthesia with propofol $3 \mathrm{mg} / \mathrm{Kg} \mathrm{IV}$, a continuous infusion of remifentanil $0,5-1 \mathrm{mcg} / \mathrm{Kg} / \mathrm{min}$ and she was intubated with a classic laryngeal mask. We also gave dexamethasone $0,1 \mathrm{mg} / \mathrm{Kg}$ IV.

We performed the PECS I ultrasound-guided block using a linear probe and with the patient in the supine position it was administered $4 \mathrm{~mL}$ of levobupivacaine $0,25 \%$. We didn't find the pectoralis major muscle but we injected the local anesthetic to spread along the fascia above pectoralis minor muscle.
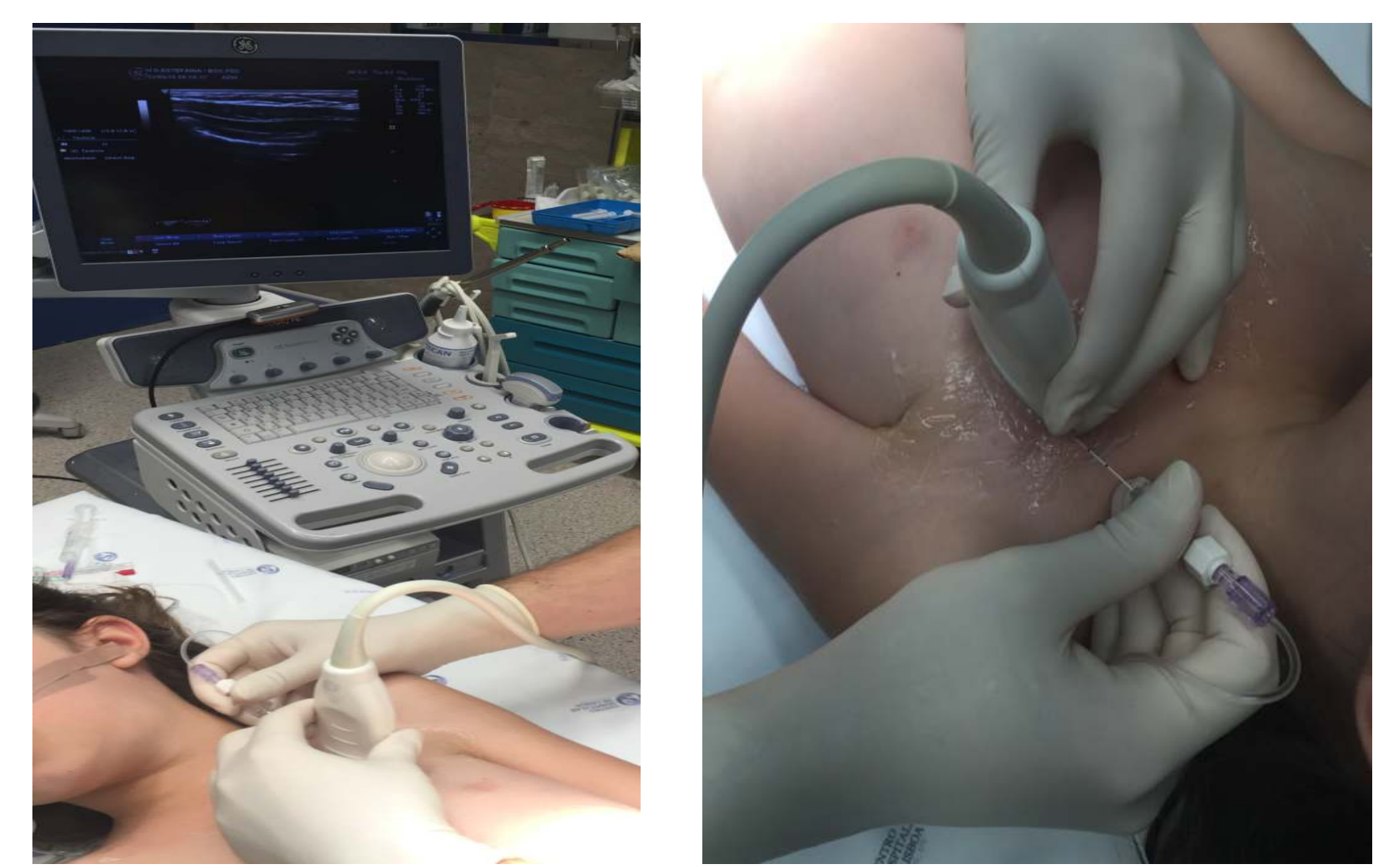

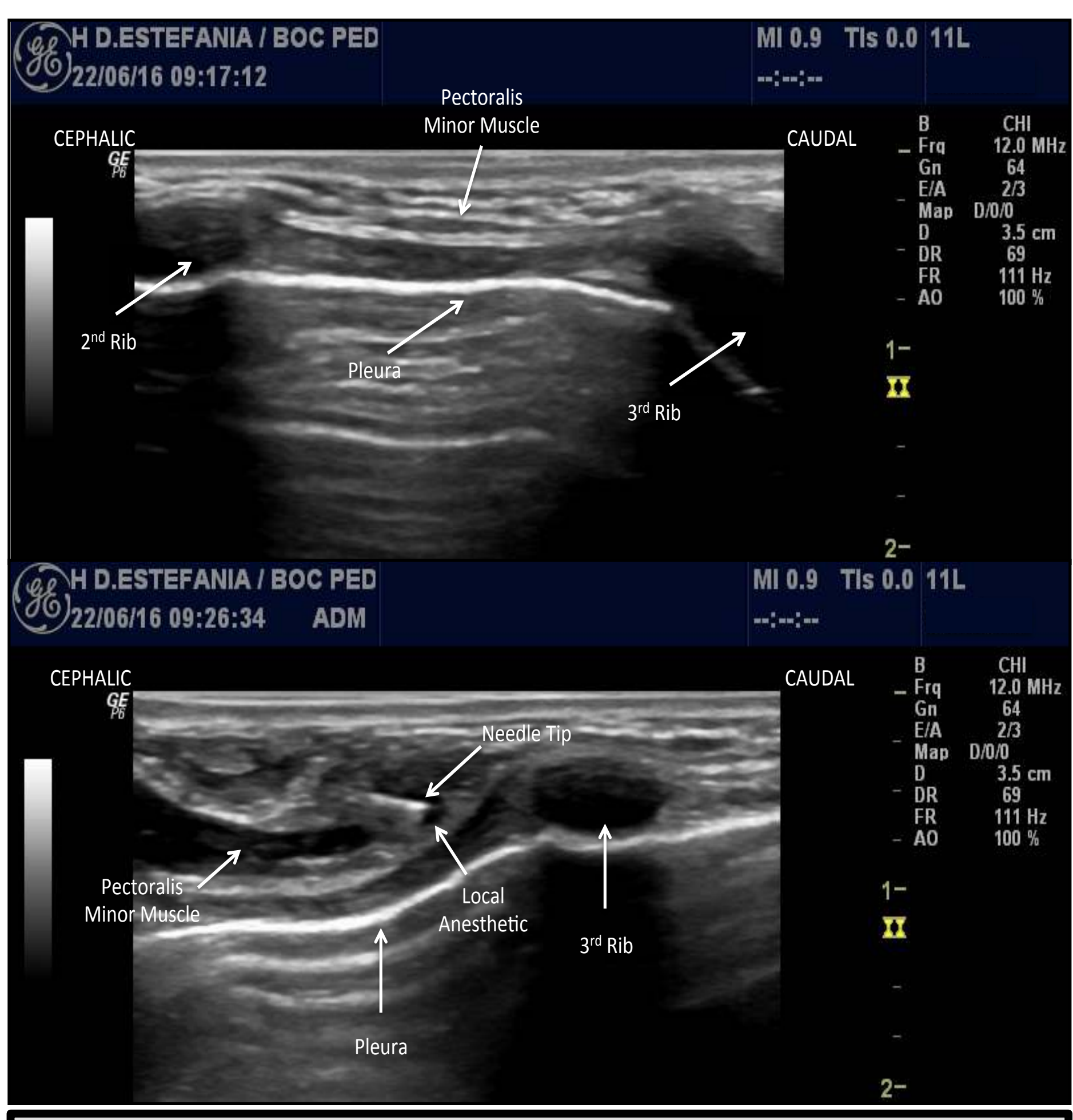

Maintenance of the anesthesia was achieved with sevoflurane/ $\mathrm{O}_{2}$ and a continuous infusion of remifentanil $0,1 \mathrm{mcg} / \mathrm{Kg} / \mathrm{min}$ the majority of the time. There were no intercurrences and it was also administered paracetamol $15 \mathrm{mg} / \mathrm{Kg}$ and ketorolac $0,5 \mathrm{mg} / \mathrm{Kg} \mathrm{IV}$. In the recovery room the patient was well awakened and had only minor pain controlled with conventional opioid-free analgesia until discharge.

DISCUSSION In this case, performing a combined anesthesia
was difficult but effective, allowing to reduce the need of
intraoperative opioid use. We didn't find in literature any report of
PECS I block in a patient without pectoralis major muscle.
LEARNING POINTS PECS I block can be challenging when the
anatomy is not that "by the book", requiring additional skills to the
anesthesiologist to perform this interfascial block and provide to
the patient a good intra and postoperative analgesia.

\section{REFERENCES}

(1) Blanco R., The "pecs block": a novel technique for providing analgesia after breast surgery. Anaesthesia 2011; 66(9):847-8.

(2) Caldas, Flávio A. A., Isa, Hellen L. V. R., Trippia, Andréia C., Bíscaro, Ana C. F. P. J., Martinez, Eliane R. C. \& Tajara, Luciana M. (2004). Síndrome de Poland: relato de caso e revisão da literatura. Radiologia Brasileira, 37(5), 381-383. 